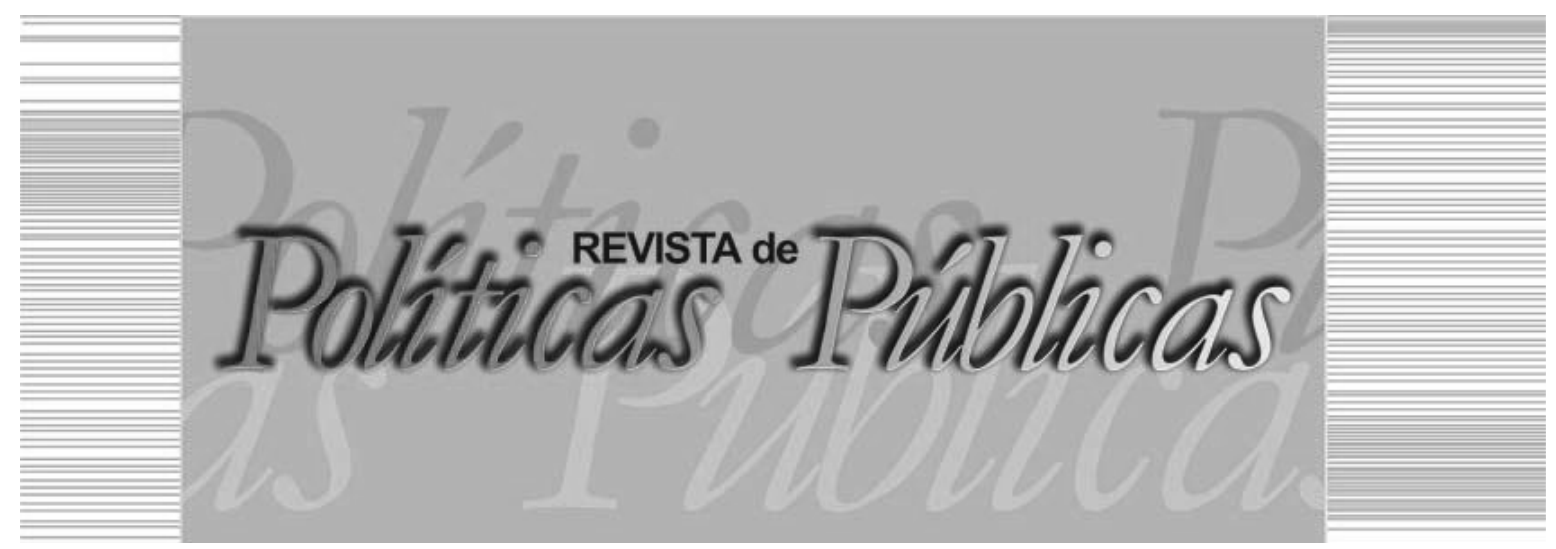

\title{
DO DIREITO CULTURAL DAS PESSOAS COM DEFICIÊNCIA
}

\author{
Patrícia Silva Dorneles ${ }^{1}$ \\ Claudia Reinoso Araujo de Carvalho ${ }^{2}$ \\ Ana Cecilia Chaves Silva ${ }^{3}$ \\ Vânia Mefano ${ }^{4}$
}

\section{Resumo}

Este artigo tem como objetivo apresentar a instituição da pauta da cidadania cultural das pessoas com deficiência junto à política nacional de cultura. Embora a pauta ainda seja frágil, observa que as poucas iniciativas até então implementadas através de ações, projetos, programas e políticas culturais acessíveis tem retirado da invisibilidade o direito cultural das pessoas com deficiência.

\footnotetext{
Graduação em Terapia Ocupacional, Doutorado em Geografia pela Universidade Federal do Rio Grande do Sul (UFRGS), Professora Adjunta III do Curso de Terapia Ocupacional da Universidade Federal do Rio de Janeiro (UFRJ). E-mail: patricia.dorneles.ufrj@ gmail.com/ Endereço: Universidade Federal do Rio de Janeiro - UFRJ: Faculdade de Medicina, Curso de Terapia Ocupacional. A. Carlos Chagas Filho n 373 - Prédio CCSBloco K - 2 andar- Sala 49, Cidade Universitária - Rio de Janeiro, RJ. CEP: 21941-702

2 Graduação em Terapia Ocupacional, Doutorado em Saúde Pública pela Fundação Oswaldo Cruz (FIOCRUZ), rofessora Adjunta do Departamento de Terapia Ocupacional da Faculdade de Medicina da UFRJ e Vice-coordenadora do Curso de Especialização em Acessibilidade Cultural do Departamento de Terapia Ocupacional da UFRJ. E-mail: claudiareinoso73@gmail.com

3 Graduação em Administração, Especialista em Acessibilidade Cultural pela UFRJ, Discente da Especialização em andamento em Gestão Pública pela Universidade Federal de São Paulo (UNIFESP). E-mail: cecilia.ufrj@gmail.com/ Endereço: Universidade Federal de São Paulo - UNIFESP: R. Sena Madureira, 1500 - Vila Clementino, São Paulo - SP. CEP: 04021-001

4 Graduação em Terapia Ocupacional, Mestrado em Saúde Pública pela Fundação Oswaldo Cruz (FIOCRUZ), Professora Assistente Efetiva do Departamento de Terapia Ocupacional da UFRJ. E-mail: vidamefano@yahoo.com.br
} 
Propõe um breve esclarecimento sobre acessibilidade cultural e pessoas com deficiência e apresenta um histórico da inserção do direito cultural da pessoa com deficiência nas políticas culturais, a contribuição de diferentes atores do campo das políticas culturais e direitos culturais das pessoas com deficiência na inserção qualificada da temática da cultura na atual Lei Brasileira de Inclusão, bem como os desafios atuais da qualificação e fortalecimento da pauta junto as políticas culturais.

Palavras-chaves: Acessibilidade, pessoas com deficiência, cidadania cultural, política cultural, inclusão.

\title{
THE CULTURAL LAW OF PEOPLE WITH DISABILITIES
}

\begin{abstract}
This article aims to present the institution of the agenda of cultural citizenship of people with disabilities next to the national culture policy. Although the agenda is still fragile, it obseves the initiatives until now implemented through accessible cultural actions, projects, programs and policies have removed the cultural rights of persons with disabilities from invisibility. It is proposed a clarification on cultural accessibility and people with disabilities, to present a history of the insertion of the cultural right of the person with disability in cultural policies, the contribution of the actors in the field of cultural policies and cultural rights of people with disabilities in the qualified insertion of the theme of culture in the current Brazilian Inclusion Law, as well as the current challenges of qualification and fortification of the agenda with cultural policies.
\end{abstract}

\section{INTRODUÇÃO}

A pauta da acessibilidade cultural para pessoas com deficiência é recente junto às políticas, projetos, programas e ações culturais. Como um campo em construção, a acessibilidade cultural deve ser inicialmente compreendida como o direito de vivenciar experiências de fruição cultural com igualdade de oportunidades para diversos públicos, entre eles, pessoas com deficiência e mobilidade reduzida.

Apesar de recente, a legislação brasileira é abrangente na garantia dos direitos culturais da pessoa com deficiência. O tema está presente em diferentes artigos e decretos constitucionais ${ }^{1}$.

A legislação brasileira outorga garantias do direito cultural da pessoa com deficiência em diferentes artigos e decretos constitucionais. A legislação nacional se espelha em tratados internacionais, pois o movimento internacional tem grande papel no curso dos movimentos sociais de temas que não pertencem à agenda de go- 


\section{DO DIREITO CULTURAL DAS PESSOAS COM DEFICIÊNCIA}

verno. Trazem parâmetros de qualidade e possibilitam a ampliação da discussão. (MEFANO, 2015). No caso da cultura, os princípios da Declaração Universal dos Direitos Humanos (ONU) a Convenção sobre a Proteção e Promoção da Diversidade das Expressões Culturais, adotada pela Conferência Geral da Organização das Nações Unidas para a Educação, a Ciência e a Cultura (UNESCO), em outubro de 2005, ratificada pelo Congresso Nacional brasileiro e a Convenção Internacional dos Direitos das Pessoas com Deficiência (2009) foram determinantes para as conquistas legais.

Não obstante os avanços na legislação, ainda se observa certa disparidade entre o que diz a lei e a prática, bem como persistem os desafios atuais da qualificação e fortalecimento da pauta junto às políticas culturais. Nesse sentido, o objetivo deste artigo é apresentar a instituição da pauta da cidadania cultural das pessoas com deficiência junto à política nacional de Cultura. Busca-se discutir a questão da acessibilidade cultural e pessoas com deficiência, por meio de uma breve contextualização da deficiência, das políticas culturais e das iniciativas de acessibilidade cultural para pessoas com deficiência e suas relações com a política nacional de cultura. O artigo apresenta, ainda, o Curso de Especialização em Acessibilidade Cultural como um dispositivo técnico-político de implementação da pauta de acessibilidade cultural junto às políticas culturais.

\section{ELEMENTOS CONTEXTUAIS E TEÓRICOS DA DEFICIÊNCIA}

O quantitativo da população mundial em 2011 era de 7 bilhões de habitantes, e, destes, segundo o Relatório Mundial Sobre a Deficiência (2011), estima-se que aproximadamente 1 bilhão (1.071.000.000) de pessoas apresentavam deficiência moderada ou severa $=15,3 \%$ da população mundial e 203 milhões de pessoas com deficiência severa $=2,9 \%$.

O Washington Group on Disability Statistics -GW é um grupo no âmbito da Organização das Nações Unidas que se ocupa de elaborar proposta de padronização das estatísticas das pessoas com deficiência, e o Instituto Brasileiro de Geografia e Estatística (IBGE) é membro efetivo e ativo desde sua criação em 2001.

Segundo dados do IBGE (2011), cerca de 45.606.048 $(23,91 \%)$ da população brasileira se diziam ter alguma deficiência. No entanto, esses dados não são base para o planejamento de políti- 
cas públicas para pessoas com deficiência, pois neles estão pessoas com perdas funcionais que não caracterizam deficiência. São os sujeitos alvo das políticas, os 15.750 .969 habitantes, que correspondem a $8,27 \%$ da população brasileira e que apresentam deficiência de moderada a grave, de caráter permanente, mesmo fazendo uso de diferentes recursos de facilitação para promoção de interação e autonomia ${ }^{2}$.

Em todos os países, grupos vulneráveis, como mulheres, pessoas no limiar de pobreza extrema, e idosos apresentaram incidências superiores de deficiência. Para todos esses grupos a taxa é superior nos países em desenvolvimento. A prevalência da deficiência nos países de renda mais baixa entre pessoas com idades de 60 anos ou mais, por exemplo, foi de $43,4 \%$, se comparada a $29,5 \%$ nos países com renda mais elevada. (Relatório Mundial sobre deficiência -2011).

No Brasil, a análise dos dados do IBGE (2011) retratam uma estreita relação entre deficiência, pobreza e precárias condições de vida. Na população de 15 anos ou mais de idade com pelo menos uma deficiência investigada, verificou-se que: $61,10 \%$ não têm instrução nenhuma ou possuem o ensino fundamental incompleto, $14,20 \%$ têm fundamental completo e médio incompleto, $17,70 \%$ têm ensino médio completo e superior incompleto, $6,70 \%$ têm superior completo e $0,40 \%$ indeterminado.

Estudiosos da população com deficiência têm destacado a existência de um círculo vicioso entre a pobreza e a deficiência. As pessoas pobres têm maior risco de adquirir uma deficiência devido à falta de acesso à boa alimentação, aos serviços de saúde, saneamento, etc. A deficiência tem levado barreiras à educação, ao emprego, e aos serviços públicos que poderiam contribuir para tirar as pessoas com deficiência da pobreza.

Segundo a Organização Mundial de Saúde (OMS) e Organização das Nações Unidas (ONU), 87\% das crianças com deficiência vivem nos países do Sul e somente $20-30 \%$ delas vão à escola. 400 milhões de pessoas com deficiência vivem nos países em vias de desenvolvimento.

Ao se debruçar sobre a relação deficiência e sociedade, verificam-se os modelos paradigmáticos desenvolvidos na história da humanidade até então. $\mathrm{O}$ modelo de rejeição à pessoa com defici- 


\section{DO DIREITO CULTURAL DAS PESSOAS COM DEFICIÊNCIA}

ência ocorreu da antiguidade até o século XIX. Para os estudiosos, este modelo é considerado a etapa da exclusão. O modelo assistencialista se inicia a partir de 1910, é o tempo da institucionalização, considerando uma etapa da segregação. Nessa etapa, as pessoas com deficiência foram retiradas de suas casas e comunidades de origem e segregadas em instituições residenciais ou escolares, geralmente por instituições sustentadas por ações assistencialistas e casas de caridade e ficavam mantidas em isolamento do resto da sociedade; fosse a título de proteção, tratamento ou processo educacional. (ARANHA, 2001).

A partir dos anos 40, inicia-se o modelo médico da deficiência, um período considerado como etapa da integração, onde surgem os atendimentos nos serviços públicos e particulares de reabilitação física e profissional. (ARANHA, 2001).

A Declaração dos Direitos Humanos em 1948 - ONU é um marco para se pensar os processos de desinstitucionalização. Alicerçados nos princípios da Declaração, os movimentos sociais das pessoas com deficiência são apoiados na teoria da normalização. Aranha (2001) expõe que nesse período iniciam processos de reivindicação e conquistas na implementação de programas comunitários que ofertassem atendimento às pessoas com deficiência.

A Teoria Social da Deficiência surge no Reino Unido e nos Estados Unidos entre os anos 60 e 70. E estruturante para a etapa da inclusão, conquistada pelo movimento de luta das próprias pessoas com deficiência. Um intelectual importante na constituição dessa perspectiva foi o sociólogo e deficiente físico Paul Hunt, que baseado nos conceitos de estigma de Goffman (1982), aponta a necessidade de se constituir um olhar sobre a deficiência a partir de uma perspectiva sociológica. Goffman (1982, p.11-12) aponta que "[...] a sociedade estabelece os meios de categorizar as pessoas e o total de atributos considerados como comuns e naturais para os membros de cada uma dessas categorias". Assim, o estranho que se apresenta com atributos que o torna diferente dos outros é incluído em categorias que faz com que este diferente se torne menos desejável e seja desconsiderado como um sujeito comum. "É esta desvantagem que, especialmente quando o seu efeito de descrédito é muito grande algumas vezes ele é também considerado um defeito, uma fraqueza, uma desvantagem." (GOFFMAN, 1982, p. 12). 
A partir de artigos e pautas, Hunt fez grandes provocações à sociedade, fortalecendo, assim, os movimentos das pessoas com deficiência. Fez-se necessária a constituição de um novo arcabouço teórico. Nesse período, as pessoas com deficiência, através de suas organizações, movem as preocupações para o campo de direitos, em especial a luta pela cidadania e seus protagonismos como sujeitos de sua própria história. $\mathrm{O}$ foco até então centrado no sujeito, passa a ter como fator central a opressão social por meio das barreiras tanto atitudinais quanto arquitetônicas.

Os movimentos sociais das pessoas com deficiência tiveram uma grande influência na emergência sobre a interpretação sociológica da deficiência e foram denominados de Disabylity Rigths Movement, ${ }^{3}$ criados a partir da década de $1970 \mathrm{em}$ países da América Latina e da América do Norte, África e Europa. Em 1976, Hunt e seus pares criam a Union of The Physically Impaired Against Segregation ${ }^{4}$. Diniz (2007) destaca que a UPIAS se tornou uma grande rede política que questionava o modelo médico da deficiência, deslocando assim a deficiência de uma questão individual para uma questão social. A opressão vivenciada pela questão da deficiência deveria ser de responsabilidade da sociedade e não mais do indivíduo. "É a incapacidade da sociedade de prever e incorporar a diversidade." (DINIZ, 2007, p.15).

O modelo social caracteriza a deficiência como um fenômeno sociopolítico: as desvantagens não resultam da lesão, mas do cenário social e das incapacidades sociopolíticas de lidar com a deficiência. A resposta, nesse modelo, não pode ser exclusivamente médica, demandando ações políticas e intervenção do Estado. (LEÃO; LIMA 2011).

Além da UPIAS, outro movimento que teve importante atuação no que tange às questões relacionadas às pessoas com deficiência, foi o Independent Living Movement (ILM), nos Estados Unidos da América, também liderado por pessoas com deficiência. Os idealizadores desse movimento criaram em 1972 um espaço denominado Center of Independent Lives (CILs) com o lema Nada sobre nós, sem nós. Esses centros passaram a ser implantados em vários países, inclusive no Brasil. Com uma proposta da oferta de serviços e sistemas de apoio que possibilitassem às pessoas com deficiência serem independentes e viverem como os demais, o ILM não somente prezava pela independência, mas também que esse público pudesse ter 


\section{DO DIREITO CULTURAL DAS PESSOAS COM DEFICIÊNCIA}

a possibilidade de escolher entre as diferentes opções da vida. Para tal, era necessário que essas pessoas conhecessem seus direitos, levando em consideração que, em muitos países, os direitos humanos básicos, muitas vezes eram negados a esse público, pelo acesso limitado aos serviços de saúde, educação, oportunidades de emprego, entre outros. (RIBEIRO; SILVA, 2017).

O movimento internacional provoca novas transformações. O ano de 1981 torna-se o Ano Internacional da Deficiência; em 1982, a Resolução $n^{0}$ 37/1982, da Assembleia-Geral das Nações Unidas, institui o Programa de Ação Mundial para as Pessoas com Deficiência. No ano de 1999 realiza-se a Convenção Interamericana para a Eliminação de Todas as Formas de Discriminação contra as Pessoas Portadoras de Deficiência (OEA). E em 2001, realiza-se a Assembleia Mundial da Saúde, que aprovou a Classificação Internacional de Funcionalidade, Incapacidade e Saúde (CIF).

O movimento internacional reverbera no Brasil, e o movimento político das pessoas com deficiência no país atua em prol do direito de sua cidadania e do protagonismo de suas próprias vidas, em igualdade de oportunidade com o restante da população. É a partir de 1979, portanto, que se constituem os movimentos das pessoas com deficiência de forma fortalecida em suas pautas.

O movimento nacional desempenhou um papel de importância na inclusão do Brasil na lista de signatários da Convenção dos Direitos das Pessoas com Deficiência da ONU em 2008, que foi recepcionada com status de equivalente a emenda constitucional

\subsection{Acessibilidade cultural e pessoas com deficiência}

De acordo com Sarraf (2012, p. 68), para se promover a inclusão de pessoas com deficiência nos espaços culturais é necessário garantir que todos aqueles que tenham o desejo de se beneficiar de tais equipamentos não sejam excluídos por conta de diferentes formas de locomoção, cognição e percepção. Desta forma, continuando o diálogo com a autora, a "[...] acessibilidade nos espaços culturais pressupõe o desenvolvimento de novas estratégias de mediação, nas quais todos os sentidos inerentes à percepção sejam envolvidos".

O conceito de acessibilidade é um conceito em evolução. Nos documentos legais, como o art. $8^{\circ}$ do Decreto Federal n ${ }^{0}$ 5.296/2004, a acessibilidade tem sido definida, de forma geral, como a remoção 
de barreiras atitudinais, físicas, arquitetônicas, de comunicação e informação.

No art. $9^{\circ}$ da Convenção Internacional dos Direitos das Pessoas com Deficiência (Nova York, 2009), ratificada no Brasil em 2009, através do Decreto Federal no 6.949/2009, destaca-se a intenção de implementação de acessibilidade através de medidas de acesso aos serviços e instalações abertos ao público ou de uso público, tanto na zona urbana como na rural.

Nas políticas culturais, até a realização da Oficina de Políticas Públicas de Cultura para Pessoas com Deficiência, em 2008, pela Secretaria de Identidade e Diversidade Cultural (SID), do Ministério da Cultura (MinC), a compreensão sobre acessibilidade cultural se limitava a uma perspectiva econômica. Assim, promover a acessibilidade cultural se resumia a ofertar por valores inferiores, ou mesmo distribuir gratuitamente, ingressos de espetáculos artísticos, programas e apresentações de projetos vinculados a Lei Rouanet.

\subsection{Políticas culturais e Acessibilidade cultural para Pessoas com deficiência: a particularidade do Brasil}

Grande parte da demanda da sociedade civil em relação à pauta de uma política cultural para a produção estética e artísticas das pessoas com deficiência, incluindo a pauta da acessibilidade cultural junto ao MinC, veio do grupo articulado do movimento Artes sem Barreiras. O Arte sem Barreiras reúne um grupo de artistas e profissionais com ou sem deficiência, das áreas das artes em geral, que nos anos 90, se constituiu como um trabalho articulado em rede nacional de forma voluntária com o objetivo de mapear iniciativas e produções artísticas para articular fomento, difusão e qualificação profissional dos grupos e indivíduos envolvidos com o direito cultural das pessoas com deficiência.

A rede inicialmente foi fomentada a partir da Fundação Nacional das Artes (FUNARTE/RJ) através de uma figura preciosa ao grupo, a então funcionária de carreira da instituição, senhora Albertina Brasil $1^{5}$. Albertina, sensibilizada por experiências internacionais da associação Very Special Arts inicia um trabalho no Brasil, institui o Programa Arte sem Barreiras na FUNARTE/RJ em parceria com diferentes atores do campo da produção cultural e artística junto a pessoas com deficiência. 


\section{DO DIREITO CULTURAL DAS PESSOAS COM DEFICIÊNCIA}

O programa teve pouco apoio do próprio MinC, mas é junto com as iniciativas do Ministério da Educação (MEC) de promoção dos encontros nacionais de arte-educação, coordenados pela Ana Mae Barbosa ${ }^{6}$, que o tema e as experiências encontram um terreno acolhedor para difusão, articulação e mapeamento das iniciativas nacionais. Albertina com outros colegas da FUNARTE/RJ e os atores da sociedade civil envolvidos na temática constituem uma representação institucional, a organização da sociedade civil Arte sem Barreiras, e iniciam um trabalho com representações regionais a partir de indivíduos e de coletivos, instituições parceiras e por segmento artístico.

As representações regionais serviram de mobilizadores locais articulados aos intercâmbios nacionais do trabalho em rede, e os grandes encontros aconteciam nos Festivais Artes sem Barreiras, acolhidos nos encontros organizados pelo MEC. Como resultados da atuação desse grupo, entre tantos outros, observa-se a visibilidade da produção estética e artística da pessoa com deficiência, a rica troca de experiências e a qualidade do trabalho em rede, o fortalecimento do campo político da cidadania cultural das Pessoas com Deficiência, a construção da rede nacional Artes sem Barreiras, com núcleos específicos de dança, teatro, artes visuais entre outros e o seu legado cultural e artístico para a diversidade da cultura brasileira.

A separação institucional da ONG Artes sem Barreiras com a FUNARTE/RJ ocorre nos anos 2000. Albertina falece. O grupo Arte sem Barreiras busca novos apoios para dar continuidade a suas ações. A gestão da FUNARTE/RJ do ano de 2006, atendendo as demandas do grupo e de outros atores da pauta, realiza com o apoio da Caixa Econômica Federal o edital Além dos Limites que apoia iniciativas, indivíduos, promove debates, qualificação e circulação dos projetos artísticos premiados. No fim de 2007, a FUNARTE passa a política de cultura para pessoas com deficiência para SID, cujo secretário era o Sr. Sérgio Mamberti ${ }^{7}$ Uma das razões desta transferência da pauta está em que esta mesma secretaria, no ano de 2007, em parceria com a Fundação Osvaldo Cruz (FIOCRUZ), realizou a Oficina Nacional de Politicas Culturais para pessoas em sofrimento psíquico e vulnerabilidade social, chamada Loucos pela Diversidade. Em 2008 a SID lança o edital de premiação Loucos pela Diversidade, homenageando o autor do livro Bixo de Sete Cabeças - Austregésilo Carrano ${ }^{8}$. Em 2011, o MinC lança o edital Albertina Brasil 
para as iniciativas de arte e cultura inclusiva pela então Secretaria de Cidadania e Diversidade Cultural.

Em agosto de 2008, a SID organiza a Oficina Nacional de Políticas Públicas para Pessoas com Deficiência, chamada Nada sobre nós sem Nós; o nome é sugerido pelos colaboradores e consultores da organização e faz referência ao lema de luta do movimento internacional das pessoas com deficiência, promovida pela então SID em parceria com a FIOCRUZ. Sabe-se que a referida oficina se tornou um marco importante na pauta da acessibilidade cultural para as pessoas com deficiência. A oficina, realizada em 2008, mesmo ano em que o Brasil se torna signatário da Convenção dos Direitos das pessoas com deficiência, é um resultado dos compromissos do MinC, junto a uma demanda latente da sociedade civil que atuava no período no campo da produção e difusão artística e cultural das pessoas com deficiência. A iniciativa de estruturar uma política para este segmento cultural refletia-se também com o compromisso do MinC e do estado brasileiro em relação à Convenção da Proteção e Promoção das Expressões da Diversidade Cultural, realizada em 2005 pela UNESCO, do qual o Brasil se torna signatário no mesmo ano.

A oficina Nada Sobre Nós Sem Nós foi constituída por um trabalho participativo junto com a sociedade civil e instituições que tinham expertise na temática. Reuniram cerca de 60 convidados, e após um dia de seminário, reuniram-se em outros dois dias para construir ações e diretrizes para a política nacional de cultura que envolvesse a temática de difusão, fomento, patrimônio da produção estética, artística e cultural para pessoas com deficiência. A temática de acessibilidade cultural aparece como uma nova demanda a ser pensada e incorporada nos Grupos de Trabalho (GT). No início há um questionamento entre os organizadores se o tema de acessibilidade cultural não deveria ser incorporado junto aos GTs de difusão, patrimônio e fomento de forma transversal. Decidiu-se que o tema de acessibilidade merecia um destaque pela sua importância e pouco conhecimento em relação ao assunto. Assim, diferente das outras oficinas de organização de ações e diretrizes organizadas pela SID, a oficina dirigida à política de pessoas com deficiência incorporou mais um GT, o de acessibilidade.

No exercício das políticas públicas culturais observa-se pouco conhecimento sobre o tema da acessibilidade cultural para pes- 


\section{DO DIREITO CULTURAL DAS PESSOAS COM DEFICIÊNCIA}

soas com deficiência, reduzindo-o na perspectiva da acessibilidade física do espaço e não do produto ou objeto cultural. Um marco de inclusão da pauta da acessibilidade cultural para pessoas com deficiência nas políticas culturais foi a Oficina Nacional de Políticas Culturais para pessoas com deficiência - Nada Sobre nós sem nós, realizada no ano de 2008 na cidade do Rio de Janeiro, promovida pela antiga SID do Ministério da Cultura e a FIOCRUZ. Entre os objetivos da Oficina estavam o escutar, conhecer e sistematizar as experiências no campo da interface de políticas e produção estética, artística e cultural das/e para as pessoas com deficiência. Construir, a partir dos Grupos de Trabalho sobre o fomento, patrimônio, difusão e acessibilidade ações e diretrizes orientadoras para uma política pública cultural para pessoas com deficiência. Entre os resultados, destacam-se ampliação e fortalecimento do debate sobre o tema e o direito da cidadania cultural da pessoa com deficiência nas conferências municipais, estaduais e nacional de cultura. (DORNELES; CARVALHO; SILVA, 2017).

Somando as ações e diretrizes para uma política pública cultural para pessoas com deficiência, registra-se também na publicação dos resultados da Oficina Nada sobre nós sem nós, a Nota Técnica ${ }^{\circ}$ 001/2009, construída pelos funcionários do MinC envolvidos com a política de acessibilidade no período, a partir das sugestões e resultados dos GTs. Entre as propostas da nota técnica, apresenta-se a incorporação da política de acessibilidade na Lei Rouanet, nos sites e editais do MinC de forma geral, a importância da implementação de uma política de livre acesso, a incorporação da acessibilidade nas produções culturais do órgão e o diálogo com os outros ministérios para ampliar a articulação interinstitucional para a implementação das políticas de fomento, difusão, patrimônio e acessibilidade junto às produções estéticas e artísticas das pessoas com deficiência. Entre os desafios, ficaram registrados no período: ampliar a compreensão do conceito de acessibilidade cultural para além da gratuidade e de valores acessíveis para espetáculos e outros produtos culturais financiados pela Lei Rouanet; e compreender e fomentar a aplicabilidade de acessibilidade cultural nas políticas e gestões públicas culturais, no que diz respeito ao direito de fruição estética, ampliando os formatos de acessibilidade dos diversos produtos culturais.

A partir da oficina realizada em 2008, registram-se novas iniciativas do MinC em relação à acessibilidade cultural. A saber: Em 2010 a Secretaria do Audiovisual, através da Programadora Brasil, 
inclui 30 filmes com audiodescrição que fazem parte dos kits distribuídos pelo programa; em 2011 o MinC lança edital Prêmio Arte e Cultura Inclusiva - 30 iniciativas culturais voltadas para o setor premiadas. Essa política vem sendo desenvolvida pela Secretaria da Cidadania e Diversidade Cultural (SCDC); em 2012 o Instituto Brasileiro de Museus (IBRAM) lança o Cadernos Museológicos 2 com o tema especial Acessibilidade a Museus. $\mathrm{O}$ ano de 2013 registra um fortalecimento da pauta através de diferentes iniciativas. É neste ano que foi publicada a Instrução Normativa (IN) da Lei Rouanet que prevê medidas de acessibilidade cultural; em parceria com a Universidade Federal do Rio de Janeiro (UFRJ), o MinC realiza a primeira turma do Curso de Especialização de Acessibilidade Cultural, ocorre a inclusão da rubrica de acessibilidade cultural nos editais dos Pontos de Cultura, de valor de $2 \%$ a 5\% do total do projeto cultural do Ponto; em 19 de Setembro lança-se o Dia Nacional do Teatro Acessível, ideia do Deputado Federal Jean Willys - Projeto de Lei 129/2013 em parceria com a Escola de Gente/ RJ; ocorre a criação do Grupo de Trabalho Interministerial de Acessibilidade: GTI - SCDC/MinC e Secretaria de Direitos Humanos da Presidência da República (SDH/PR); e lança-se o edital projeto Acessibilidade em Bibliotecas Públicas, parceria MinC e a ong e Mais Diferença. Em 2015, o Brasil aprovou o Tratado de Marraqueche na forma qualificada prevista no $\S 3^{\circ}$ do artigo $5^{\circ}$ da Constituição Federal, conforme o Projeto de Decreto Legislativo 347, de 9 de setembro de 2015 do Senado Federal. Cabe salientar, ainda, que a pauta da acessibilidade cultural é destacada no Plano Nacional de Cultura (PNC), através da meta 29 , que nos desafia a atingir "[...] $100 \%$ de bibliotecas públicas, museus, cinemas, teatros, arquivos públicos e centros culturais atendendo os requisitos legais de acessibilidade e desenvolvendo ações de promoção da fruição cultural por parte das pessoas com deficiência”. (BRASIL, 2010, p. 12).

\subsection{O Curso de Especialização em Acessibilidade Cultural como um dispositivo técnico-político de implementação da pauta de acessibilidade cultural junto às políticas culturais}

O Curso de Especialização em Acessibilidade Cultural, desenvolvido pelo Departamento de Terapia Ocupacional da UFRJ em parceria com a SCDC do MinC, é uma iniciativa pioneira no que diz respeito à formação na temática. 


\section{DO DIREITO CULTURAL DAS PESSOAS COM DEFICIÊNCIA}

Assim, o referido curso tem sido um instrumento de fortalecimento da política cultural para pessoas com deficiência. Nas duas edições do projeto em parceria com o MinC, desenvolveu-se uma série de ações culturais como uma contrapartida dos discentes ao investimento público oferecido pela formação gratuita. Dessa forma, a cada edição é apresentada junto ao edital um compromisso de envolvimento com a pauta da acessibilidade cultural, onde o candidato deve estar ciente das responsabilidades a serem assumidas após o Curso, ou seja, o aluno deve estar comprometido em ser multiplicador do tema e da formação, antes, durante e após a capacitação oferecida pela pós-graduação.

Na primeira edição do curso, junto à realização do I Encontro Nacional de Acessibilidade Cultural (ENAC), realizou-se a Conferência Livre de Acessibilidade Cultural para pessoas com deficiência. As propostas apresentadas foram qualificadas pelos discentes da turma ao longo da formação, finalizando um documento com 90 propostas para a III Conferência Nacional de Cultura, sendo a Conferência Livre de Acessibilidade Cultural a que mais apresentou propostas para a Conferência Nacional. Além disso, os discentes foram mobilizados para que defendessem as propostas nas conferências municipais e estaduais de cultura. Como resultado, chegamos a oito delegados estaduais e dois nacionais. Na conferência nacional, junto a outros pares da luta pela acessibilidade cultural, aprovamos a proposta $3.18^{9}$ como prioritária do eixo IV Direitos Humanos e Cultura.

Na segunda edição do curso, a parceria com a Universidade Federal do Rio Grande do Sul (UFRGS) na realização do Curso de extensão de $40 \mathrm{~h}$ em formato de ensino a distância em Acessibilidade em Ambientes Culturais, possibilitou a capacitação de 420 interessados na temática. Os discentes da especialização, anteriormente capacitados pela equipe da UFRGS, tornaram-se multiplicadores de uma edição. Registraram-se 1.600 candidatos em três dias de inscrições. A falta de formação no Brasil e o crescente interesse pelo tema vêm cada vez mais buscando interessados.

O Curso tem possibilitado ao MinC, que este órgão atenda o item 2.9 do Sistema Nacional de Cultura (SNC) que aponta para a implementação de Política Nacional de Formação na área da Cultura. Ao instituir a Rede de Articulação, Fomento e Formação, comentada a seguir, observa-se que o curso se insere no 2.9.2 do Sistema Nacional de Cultura, que pauta a Criação da Rede de Instituições 
de Formação na área da cultura, e no item 2.9.3. implementação de Programa de Formação na área da cultura.

Deve-se ressaltar, também, a produção cientifica dos discentes. Atualmente temos uma média de 77 trabalhos de conclusão de curso que ficam disponíveis no site do mesmo para acesso geral dos interessados. Essa produção tem se tornado referência bibliográfica importante para a área, já que a formação no Brasil é muito restrita, não havendo outro curso de pós-graduação especifico com o tema da acessibilidade cultural. Registra-se que a pesquisa em políticas culturais é recente no país. As pesquisas dos discentes da especialização da UFRJ vêm fazendo a diferença e incluindo a temática nos poucos encontros, seminários e publicações sobre políticas culturais. Analisando os trabalhos finais das duas turmas, os temas foram diversos e puderam ser categorizados em seis grandes grupos: Políticas Culturais- trabalhos que discutem a legislação pertinente ao campo da Cultura, bem como as metas do Plano Nacional de Cultura e o direito; Acessibilidade nos Pontos de Cultura - trabalhos cujo tema principal se refere aos Pontos de Cultura; Acessibilidade em equipamentos culturais- trabalhos que analisaram e discutiram a acessibilidade em museus, bibliotecas, espetáculos teatrais, feira literária e em um circuito cultural da cidade.; Formação profissional- trabalhos que versaram sobre as experiências de acessibilidade no contexto de formação, por exemplo, a oferta de disciplina específica de acessibilidade cultural, assim como a dificuldade de se acolher deficientes em instituições de ensino superior; Recursos de acessibilidade- trabalhos cujo tema central são os recursos de acessibilidade; Acessibilidade no contexto da deficiência - trabalhos que têm o contexto da deficiência como tema principal.

A Lei Brasileira de Inclusão, aprovada no ano de 2016, apresenta conquistas importantes dos trabalhadores da área cultural que militam pela cidadania cultural das pessoas com deficiência. O capítulo VII Do direito à cultura, ao desporto, ao turismo e ao lazer se dedica a orientar o tratamento prioritário às pessoas com deficiência, à comunicação adequada, à promoção de acesso aos espaços culturais, à criação de incentivos para a participação de atividades criativas e à participação das pessoas com deficiência em concursos no campo das artes em geral.

A lei também aponta que cada órgão do poder público que atue com cultura deve criar uma coordenadoria ou gerência de inte- 


\section{DO DIREITO CULTURAL DAS PESSOAS COM DEFICIÊNCIA}

gração das ações voltadas para pessoas com deficiência. Essa é uma demanda fundamental para implementar os recursos de mediação cultural nos ambientes culturais. A lei também apresenta porcentagens de recursos financeiros para desenvolvimento de projetos e programas, destina porcentagens de recursos para inclusão, apresenta formas de incentivo fiscal a pessoas físicas e jurídicas, aos apoiadores de tais iniciativas. Ainda na abordagem percentual, a lei versa sobre as reservas de lugares para pessoas com deficiência, bem como sobre a qualidade de suas acomodações.

É interessante destacar que a lei acolhe as demandas dos artistas com deficiência, no art. $81^{\circ}$, orientando que coxias e camarins devem ser acessíveis às pessoas com deficiência. Definições sobre orientações a respeito de sonorização, prazo de aplicabilidade das adaptações nos espaços públicos e privados, orientações sobre as formas de comunicação acessíveis também são apresentadas. (BRASIL, 2015).

\section{CONCLUSÃO}

Conclui-se que a pauta, apesar de seu avanço, deve ser fortalecida. Os direitos dos deficientes, já garantidos na legislação, necessitam se converter em direitos efetivos, capazes, realmente, de garantir a acessibilidade dos mesmos à fruição cultural.

A Lei Brasileira de Inclusão é, portanto, um reforço às conquistas da pauta da acessibilidade cultural. Embora a inclusão da rubrica de acessibilidade nos projetos da Lei Rouanet e nos editais de Pontos de Cultura representem um avanço concreto da implementação da política, elas por si só não bastam. É fundamental ampliar os recursos destinados à implementação da acessibilidade cultural. O pouco conhecimento dos gestores públicos sobre a demanda tem sido representado no baixo orçamento para tal, o que tem dificultado, para o realizador, cumprir suas metas de acessibilidade com qualidade nos seus produtos culturais.

Outro desafio urgente é a aproximação dos trabalhadores e gestores culturais ao conhecimento da demanda de acessibilidade cultural, bem como aos serviços a serem contratados, a qualidade dos mesmos e a aproximação com o público de pessoas com deficiência. Do mesmo modo, é hora também de as pessoas com deficiência ampliarem sua visibilidade como público e plateia junto às atividades culturais acessíveis. 
A formação e a ampliação do tema nos parecem ainda uma estratégia qualificada para vencermos os desafios da implementação da política de acessibilidade cultural para pessoas com deficiência. Dessa forma, apostamos que devem ser inseridas disciplinas obrigatórias de acessibilidade cultural para pessoas com deficiência nos cursos de produção cultural, de terapia ocupacional e licenciaturas e bacharelados artísticos. Torna-se cada vez mais importante que o futuro artista ou o professor de artes, aplique técnicas e metodologias de democratização cultural no seu produto ou conteúdo estético artístico.

Do mesmo modo, torna-se importante a criação de cursos técnicos de acessibilidade cultural para pessoas com deficiência. Estes devem atuar como mediadores nos espaços culturais. A universidade pública brasileira deve incorporar o tema e auxiliar na construção dessa política tão importante para a democratização cultural e para a promoção da cidadania cultural das pessoas com deficiência. O MinC, responsável pela implementação dessa política, deve ser um dos grandes responsáveis no fomento dessa capacitação junto a outros pares institucionais e a sociedade civil.

\section{REFERÊNCIAS}

ARANHA, M. S. F. Paradigmas da relação da sociedade com as pessoas com deficiência. Revista do Ministério Público do Trabalho, Brasília, DF, ano XI, n. 21, p. 160-173, mar. 2001. Disponível $\mathrm{em}:<\mathrm{http}: / /$ www.adiron.com.br/arquivos/paradigmas.pdf $>$. Acesso em 5 set. 2017.

BRASIL. Lei no 13.146 , de 6 de julho de 2015. Dispõe sobre a Lei Brasileira de Inclusão da Pessoa com Deficiência. Diário Oficial da União, Brasília, DF, 2015. Disponível em: $<$ http://www.planalto.gov. br/ccivil 03/ Ato2015-2018/2015/Lei/L13146.htm>. Acesso em: 4 ago. $201 \overline{5}$.

BRASIL. Ministério de Cultura. Plano Nacional de Cultural. Brasília, DF, 2010.

DINIZ, D. O que é deficiência? São Paulo: Brasiliense, 2007.

(Coleção Primeiros Passos).

DORNELES, P. S.; CARVALHO, C. R. A. de; SILVA, A. C. C.

O Curso de Pós-Graduação em Acessibilidade Cultural da UFRJ: breve estudo sobre seu papel na construção de uma política de formação, perfil dos discentes e suas contribuições de pesquisa e ação 


\section{DO DIREITO CULTURAL DAS PESSOAS COM DEFICIÊNCIA}

cultural na área. In: SEMINÁRIO INTERNACIONAL POLÍTICAS CULTURAIS FCRB, 8., Rio de Janeiro, 2017. Anais... Rio de Janeiro: Itaú Cultural, 2017. v. 1. p. 1084-1094.

GOFFMAN, E. Estigma: notas sobre a manipulação da identidade deteriorada. Rio de Janeiro: Zahar, 1982.

INSTITUTO BRASILEIRO DE GEOGRAFIA E ESTATÍSTICA. Censo Demográfico 2010: características gerais da população, religião e pessoas com deficiência. Rio de Janeiro, 2011.

LEÃO, T. M.; LIMA, I. M. S. O. Direito sanitária e pessoa com deficiência: uma análise da rede de proteção normativa à saúde no Brasil.In: LIMA, I. M. S. O; PINTO, I. C. de M.; PEREIRA, S. de O. (Org.). Politicas Públicas e Pessoa com Deficiência. Salvador: EDUFBA, 2011.

MEFANO, V. Política pública para a pessoa com deficiência: Brasil e experiência internacional. Rio de Janeiro: Escola Nacional de Saúde Pública Sérgio Arouca, 2014.

ORGANIZAÇÃO DAS NAÇÕES UNIDAS. Convenção sobre os direitos das pessoas com deficiência. [S. 1.], 2006. Disponível em: $<$ http://www.un.org/disabilities/convention/conventionfull.shtml>. Acesso em: 23 jan. 2018.

ORGANIZAÇÃO MUNDIAL DE SAÚDE. Relatório Mundial Sobre a Deficiência. São Paulo: SEDPcD, 2011.

RIBEIRO, L.; SILVA, R. Da mistificação à inclusão: influência dos modelos de compreensão de deficiência na educação especial. Revista Educação e Cultura Contemporânea, Rio de Janeiro, v. 14, n. 35, p. 341-367, 2017.

SARRAF, V. P. Comunicação dos Cinco Sentidos em Espaço Culturais. Cisc 20 anos, São Paulo, v. 1, p. 107-118, 2012.

\section{Notas:}

1 A saber: art. $215^{\circ}$ da Constituição da República Federativa do Brasil; no Decreto Federal $\mathrm{n}^{\circ} 3.298$, de 20 de dezembro de 1999, que regulamenta a Lei Federal de $\mathrm{n}^{\mathrm{0}} 7.853$, de 24 de outubro de 1989, e que foi alterado pelo Decreto Federal $\mathrm{n}^{0} 5.296$, de 2 de dezembro de 2004, que regulamenta as Leis Federais de $\mathrm{n}^{\circ} 10.098$ e 10.048 , de 8 de novembro de 2000; no Decreto Legislativo n ${ }^{\circ} 186$, de 10 de julho de 2008 e no Decreto Federal nº 6.949, de 25 de agosto de 2009, que ratificaram os princípios da Convenção sobre os Direitos das Pessoas com Deficiência, assinada em Assembleia Geral da ONU, e seu respectivo protocolo facultativo, de 6 de dezembro de 2006, sobretudo, os artigos $1^{\circ}$ a $9^{\circ}, 11^{\circ}, 23^{\circ}$ e, particularmente, $\mathrm{o}$ art. $30^{\circ}$, que dispõe sobre a participação de pessoas com deficiência na vida cultural de suas comunidades em base de equiparação de oportunidades com as 


\section{Patrícia Silva Dorneles | Claudia Reinoso Araujo de Carvalho Ana Cecilia Chaves Silva | Vânia Mefano}

demais pessoas, solicitando aos Estados Partes tomar todas as medidas necessárias nesta direção, como a produção de materiais culturais em formatos acessíveis. $\mathrm{O}$ art. $30^{\circ}$, em sua alínea 2, expressa ainda a importância dos Estados Partes executarem "[...] medidas apropriadas para que pessoas com deficiência tenham a oportunidade de desenvolver e utilizar seu potencial criativo, artístico e intelectual, não somente em benefício próprio, mas também para o enriquecimento da sociedade" (ONU, 2006 p. 19) e ao disposto no Decreto Federal $\mathrm{n}^{\circ} 5.761$, de 27 de abril de 2006, que regulamenta a Lei Federal $\mathrm{n}^{\circ} 8.313$, de 23 de dezembro de 1991; ao inciso III do artigo $10^{\circ}$ do Decreto $n^{\circ} .5 .761 / 2006$

2 Dados por deficiência: 4,45\% deficiência visual, 1,02\% deficiência auditiva, 2,33\% deficiência motora, $1,3 \%$ deficiência mental-intelectual.

3 Movimento pelos direitos dos deficientes.

4 União dos Deficientes Físicos Contra a Segregação (UPIAS).

5 Albertina Brasil fundou em 1988 o programa Artes Sem Barreiras junto com Ritamaria Aguiar. O programa tinha como objetivo valorizar o artista com deficiência.

6 Ana Mae Tavares Bastos Barbosa, educadora brasileira, pioneira em arte-educação, defende o ensino da arte em todos os níveis de educação

7 Sergio Mamberti- Secretário em 2003 da SID/MinC.

8 Ausregésilo Carrano Bueno- escritor brasileiro integrante do Movimento da Luta Antimanicomial

9 Por meio de capacitação e qualificação de recursos, implementar políticas de acesso às pessoas com deficiência, incapacidade temporária e /ou mobilidade reduzida, à produção, circulação e fruição de bens e serviços culturais ao: a)disponibilizar os sistemas de acesso aos mecanismos públicos de fomento em formato conforme o conceito de acesso universal à informação (entendendo que a LIBRAS não é uma modalidade comunicativa de acesso à Língua Portuguesa); b) garantir a presença dos itens que contemplem os recursos de tecnologia assistiva e/ou ajudas técnicas nos editais de acesso aos mecanismos de fomento; c) produzir conteúdos em formatos acessíveis através da comunicação ampliada e alternativa (CAA) para atender aqueles que têm necessidades informacionais específicas além da interpretação para a LIBRAS a fim de atender a especificidade linguística dos surdos, acerca do patrimônio cultural material e imaterial, conforme todas os níveis de ensino: fundamental, médio, superior e educação de jovens e adultos (EJA) e as características regionais; d) promover a capacitação para a Plena Acessibilidade Cultural e Artística dos agentes culturais, movimentos sociais e entidades culturais públicas e privadas, atuantes na área de educação e cultura; e) promover a capacitação dos mediadores, gestores, técnicos e avaliadores dos editais públicos tendo como condição sine qua non a participação da pessoa com deficiência para a validação do processo; f) Garantir o fomento, circulação e manutenção de artistas e coletivos com deficiência em acordo com as resoluções da Oficina Nacional de Indicação de Políticas Públicas Culturais para pessoas com deficiência gravada na Nota Técnica $n^{\circ} 001 / 2009$ da SID/MINC; g) Criar e apoiar programas, projetos e ações de acessibilidade e produção cultural nas suas dimensões arquitetônica, comunicacional, metodológica, instrumental, programática, tecnológica e atitudinal para o público, bem como para os agentes culturais, grupos coletivos e artistas que incluam pessoas com e sem deficiência. 